\title{
O POSITIVISMO E A SEPARAÇÃO ENTRE MORAL E DIREITO - RESTRIÇÕES AO PODER SUPREMO DELEGADO ATRAVÉS DO CONTRATO SOCIAL
}

\section{ARTIGO ORIGINAL}

CARNEIRO, Dioclécio Salomão ${ }^{1}$

CARNEIRO, Dioclécio Salomão. O positivismo e a separação entre moral e direito

- Restrições ao poder supremo delegado através do contrato social. Revista Científica Multidisciplinar Núcleo do Conhecimento. Ano 05, Ed. 01, Vol. 04, pp. 131 142. Janeiro de 2020. ISSN: 2448-0959, Link de acesso: https://www.nucleodoconhecimento.com.br/lei/o-positivismo

\section{RESUMO}

Em tese o estreitamento dos laços entre a moral e o direito positivado se constrói em grande escala pelo uso dos princípios, cujos denotam o que não se deve alterar e sim nortear a aplicação da norma a cada caso concreto. Desta forma, sustenta-se que para os hard cases, as decisões jurídicas prevalecem solução através de princípios. Porto outro lado, o elo de ligação entre a teoria econômica e o direito costumeiro, sugerem aos juízes o decisionismo baseado em políticas e não em princípios. A essa limitação de poder decisório, somado a necessidade de resposta eficaz que respeita o direito legislado é, portanto, a línea tênue do objeto deste trabalho. De toda forma, se um jurista pensa o direito como um sistema de regras positivadas e ainda assim o reconhece, como dever ser, logo os juízes que mudam regras antigas e introduzem novas, chegará à conclusão de uma teoria do poder discricionário judicial no sentido mais forte da palavra. Para isso os freios necessários para que se amplie a capacidade de empoderamento das leis como sendo o mais legítimo dos comandos jurídicos cujos foram construídos em tese pelos

\footnotetext{
1 Mestrando em Direito Constitucional - Direitos Fundamentais e Democracia, Bacharel em Direito e Ciências Contábeis.
} 
representantes da sociedade. Contudo o elemento de deve ser no direito e o que realmente reflete de forma fática é o estudo abordado.

Palavras-chave: Direito Constitucional, democracia, moral, poder.

\section{INTRODUÇÃO}

Contempla HART (2010), em seu estudo, que quando Bentham e Austin insistiram na distinção entre o Direito como ele é e como deveria ser, eles tinham em mente leis específicas, cujos sentidos estavam claros e, assim, não em disputa, e estavam preocupados em sustentar que tais leis, mesmo se moralmente ultrajantes, ainda eram leis. É necessário, entretanto, ao refletir sobre as críticas que surgiram posteriormente, refletirmos para além das críticas dirigidas a esse ponto específico, se queremos chegar à raiz da insatisfação que se sentia. É necessário, portanto, que se leve em consideração a objeção de que, mesmo se aquilo que os Utilitaristas sustentavam nesse ponto estivesse correto, sua insistência a seu respeito, por meio de uma terminologia que sugeria uma separação geral entre o que é e o que deveria ser o Direito, obscureceu o fato de que, em outros momentos, há um ponto de contato essencial entre os dois.

\section{A PAIXÃO POR REFORMAS COM O RESPEITO AOS DIREITOS. DA NECESSIDADE DE CONTROLE E ABUSO DO PODER. A AUSÊNCIA DE DISTINÇÃO ENTRE O QUE O DIREITO É E O QUE DEVERIA SER}

No início da década passada, mais especificamente nos últimos anos na véspera das eleições brasileiras percebeu-se uma elevação do sentimento de incertezas diante ao crime e violência evidenciados, incluídos os de corrupção e colarinho branco. Para ADORNO (1999), aos cidadãos, sem distinção de suas origens étnicas, gênero, geração, riqueza ou poder percebeu-se como ameaçado ao dispor de seu futuro e patrimônio pessoal, principalmente em consonância ao seu bem mais precioso - sua indelével vida. O que parece não se tratar de um fenômeno unicamente brasileiro. Percebe-se esse mesmo fato em países como nos Estados Unidos da 
América, Inglaterra ou mesmo na França, por adotarem comportamentos coletivos de expressão semelhantes.

Na contextualização de ADORNO (1999), no país de língua francesa, a ciência indica que a sensibilidade de medo, sensação de insegurança distinguem-se pelo crescimento da delinquência, no entanto o alto poder de deterioração de alguns bairros da periferia, além da chegada de imigrantes, levam naturalmente ao acirrado comportamento de competição por trabalho, de forma a perceber a crise na instituição da República. Para o Brasil, esse cenário demonstrado anteriormente se agrava no período de transição entre o regime autoritário e a democracia. As razões pelo que motivaram esse fenômeno ainda são obscuros na literatura.

Fator determinante na história são que os direitos universais se demonstravam como de pouca inclusão ao maior número de indivíduos. Como bem destaca as crianças, os deficientes, prisioneiros, estrangeiros, cujos estavam situados numa condição social de baixa participação no processo democrático e político das decisões que em muitas vezes decidiam seus futuros, conforme destaca HUNT (2009). As bizarrices vão muito além de excluir os cidadãos que não possuíam qualquer tipo de propriedade, escravos, ou mesmo negros livres, as minorias religiosas, mulheres, além do que independe da opção sexual. Cabe ressaltar que ainda nos dias atuais, as mulheres enfrentam duras restrições de liberdade, violência moral e física pelo fato de nascerem mulheres. Nas palavras de HUNT (2009), essas limitações cada vez mais incomodam os estudiosos a ponto de questionar-se se realmente as declarações desses direitos universais de fato garantem alguma emancipação do indivíduo, ou melhor uma espécie de emancipação política, mas que na prática não representava nada. Os que deram início, estruturara e escreveram as declarações são julgados como elitistas, racistas e até misóginos por serem incapazes de somar verdadeiramente todas as pessoas no que tange a igualdade de direitos, declarações essas evidenciadas nas decisões políticas adotadas em países de referência mundial como no caso do Brasil e Estados Unidos.

É correto, portanto, o raciocínio de LAZZARINI (1996), ao sustentar a tese em que os direitos individuais são relativizados a todo momento, a exemplo disso o próprio poder 
de polícia, ressalte-se aqui o poder do Estado, do qual deve estar controlado a ponto de não colocar em perigo a propriedade e liberdade por mera causalidade subjetiva, ou mesmo que objetiva num ato antidemocrático. O poder Estatal, bem como as restrições de direitos individuais ou mesmo sua utilização não se deve permitir o excesso ou desnecessária, sob pena de configurar abuso de poder, incluindo-se as próprias declarações da "boca do Estado", através do Presidente da República, por exemplo ao discutir assuntos de interesse nacional, cujos direitos que tangem a plena democracia não devem em hipótese alguma serem enfraquecidos, mas sim elevados ao status de garantia constitucional.

Não é aceitável que a legislação possibilite qualquer ação coercitiva autoritária para se justificar o ato de polícia. Para isso, LAZZARINI (1996), destaca a necessidade de se objetivar condições materiais que ensejem a inovação permanente de práticas democráticas. No ambiente de liberdade individual e a consonância do poder público, destaca-se a junção entre o que é necessário pelo devido respeito das liberdades individuais, mas também assegurar a ordem social. Para tanto tem-se ao lado do Estado o pressuposto de conveniência ou do interesse público, como pré-requisitos de limitação aos direitos individuais plenos, além da também observância desses mesmos direitos indelegáveis aplicados ao poder supremo relativo do Estado na condição de defesa da sociedade, mas jamais opressora para com seus direitos constitucionais.

Pode o Estado preventivo desempenhar o que considere útil e importante para a sociedade, desde que não deslegitime todo e qualquer direito, assim como as garantias individuais fundamentais de seus cidadãos. Desta forma estão descritos na própria Constituição da República Federativa do Brasil, os direitos e principalmente os trilhos democráticos por onde a atividade Estatal deve seguir com sua excepcional importância no combate às desigualdades sociais e promoção do desenvolvimento democrático sustentável e de cidadania.

Todo Estado que se diz moderno, tem a vida social governada por princípios democráticos alinhados ao cidadão, em destaque o princípio da legalidade, que somado as declarações de direitos fundamentais universais e da Constituição. Cabe 
ressaltar, conforme orienta CUNHA (2003), o Constituinte brasileiro em sua fundamentação renova a afirmação de que ninguém será obrigado a fazer ou deixar de fazer algo senão em virtude lei, situação essa enaltecida na tradição da Carta Magna inglesa e consolidada nas revoluções estadunidense e francesa. A partir disso, tem-se a lei como a expressão mais pura da vontade geral de uma nação, haja visto ter sido produzido pelas pessoas formadas pelo conjunto de cidadãos do povo em questão, partindo de uma série de manifestações oriundas e através dos agentes políticos, com mandado eletivo, assim estruturar a Casa de Leis.

E como todo sistema equilibrado e de características de formação democrática, o poder não poderá assim ser absoluto e irrestrito, para isso tem-se então a separação harmônica dos poderes constitucionais cujos são submetidos diuturnamente ao controle do Poder Judiciário. A legislação produzida que contrarie os preceitos da Constituição, mesmo que a viole em suma interpretativa é anulada e isenta de qualquer aplicação fática no campo do direito. Para CUNHA (2003), as leis ilegais se opunham para com a manifestação judicial, sendo, portanto, vedado a elas as restrições indevidas ao direito ou a própria liberdade. Contudo, o princípio legalista, se torna aperfeiçoado em que pese o exercício da vigilância constante da finalidade a que a lei se propõe a alcançar. A ilegítima lei ou ato Estatal administrativo, de conteúdo ou prática de autoridade esvaziado de competência, finalidade ou conexão interpretativa jurídica. Sendo por si, razões lógicas basilares da cláusula interpretativa cuja lei se fundamenta, no viés assim definido pela interpretação teleológica.

Para HABERMAS; REPA (1999), a passividade jurídica não deseja cercar-se do direito internacional numa condição permanente de guerra ente Estados soberanos, mas ao contrário disso superar a norma cosmopolita que de forma integral e ordeira busca a tudo "juridificar". Seguindo a linha de discussão, de Kant a Kelsen, buscouse a todo momento histórico essa tradição de tornar o direito resposta para todos os fatos, no entanto só hoje os governos sérios aplicam essa tradição em busca de um Estado estável e desenvolvido socialmente. A condição exposta do cidadão a espécie de associação universal, garantiria e protegeria o cidadão dos excessos praticados no 
cerceamento de seus direitos e arbitrariedades de governos, mas também dos demais poderes que compunham o tripé constitucional (legislativo, executivo e judiciário).

Na leitura de HABERMAS; REPA (1999), a forma de associação universal garantiria de alguma maneira a proteção do cidadão frente ao Estado autoritário ou mesmo pelas arbitrariedades produzidos durante governos transitórios. As consequências e atos responsabilizados como sendo a mais importante imposta à autonomia dos Estados, sugere-se a exemplos como o de Pinochet, cujos militares e servidores públicos foram condenados pelos crimes praticados contra a população, e também como exemplo mais recente, no caso do Brasil, a Comissão da Verdade, da qual em tempos de plena democracia ativa e atuante entre governos, consegue-se apurar fatos pretéritos ocorridos para além da investigação, direito ao controverso e ampla defesa, e seguir para condenação se comprovado os crimes enaltecidos nos exageros cometidos pelo Estado Brasileiro, motivados pela falsa ideia de tornar o país enterrado na desigualdade e privilégios, no discurso de que violência aos pobres e miseráveis seria a adequação e assentamento de um discurso de ódio, meramente conclusivo das fraquezas que o povo vivia.

Desta forma, a dogmática produzida por BARROSO (2003), fala dos diversos sistemas e princípios especiais de interpretação da Constituição, que se tornam em condição própria de superação das amarras interpretativas de conveniência, sobretudo junto as leis infraconstitucionais, no exemplo pode-se citar o Direito Civil. Destaca-se como a grande guinada para o diálogo interpretativo constitucional, de fato a constatação na crença imutável de normas jurídicas, trazendo em si mesmas um sentido único e estrito, inserido em toda e qualquer situação de fato concreto. $E$ assim não cabendo a interpretação ao caso específico, mas apenas aplicando a revelação do que a contém em letras frias, cujas tornam efeitos devastadores em alguns casos, aplicação da lei.

Entretanto a interpretação nova ou reinterpretação do que diz a Constituição, se configura no atento olhar de que relatam e o que quer expressar as cláusulas constitucionais, num efeito de proposta aberta ao intérprete, contendo em si princípios que possuem a dependência do fato real e concreto, para assim terem sentido objetivo 
daquilo que buscou ordenar. O texto normativo por si só, relaciona na maioria dos casos, uma espécie de limites e divisas a serem explorados na capacidade interpretativa, gerando possibilidades itinerantes para com o dispositivo legal do qual pretende-se inserir. Contudo os fatores que se concretizam no contexto legal, preservando-se os fins principiológicos, requer então o sentido da norma para situação analisada, no intento de se produzir a solução adequada aos preceitos constitucionais, tornando assim o intérprete e julgador, reféns da melhor e com capacidade de se auto modernizar nos nuances temporais em que os fatos da vida em sociedade, se tornam fatos jurídicos a depender necessariamente da constatação do preceito Constitucional.

\section{A EXISTÊNCIA DE LEIS MORALMENTE MÁS. O CARÁtER ESPECÍFICO DA AUTORIDADE DE UM COMANDO LEGAL. A SEPARAÇÃO ENTRE A MORAL E O DIREITO}

Neste sentido, Kant estabelece a existência de graus da virtude, vale dizer, quanto mais "por dever" uma ação é praticada e menos por algum sentimento (que mesmo benéfico à realização do dever é distinto dele), mais virtuosa a ação é. Assim, por exemplo, ajudar um desconhecido em circunstâncias adversas envolve mais virtude (ou, mais propriamente, mais mérito) do que ajudar um amigo.

Com base nesta passagem podemos entender que Kant defende com firmeza a existência de coisas que são indiferentes moralmente, pois se não se admite semelhantes coisas como tais, há uma "tirania da virtude" e os deveres tornam-se como "armadilhas", isto é, há um exagero na consideração do que é realmente relevante do ponto de vista moral. Destarte na interpretação de SANTOS (2012), há que se diferir os excessos da norma aplicada por valores pessoais de quem as replica e sim o objetivo pela qual foi criada obedecendo o comando popular em caráter de promover a justiça social.

O que difere regulamentos bons ou maus, são estritamente pela oposição do que é egoísta e aquilo que adere ao moralmente positivo possui caráter próprio por aqueles 
que são beneficiados pelo que é útil da norma. Do ponto de vista utilitário, conforme esclarece ARALDI (2016), as regras possuem o condão de censura ou elogio apenas baseando-se em seu dano ou aproveitamento usual da mesma. Do impulso egoísta ou altruísta do indivíduo, trata-se da resultante do que é ajuizado como bom ou mau. Nesse contexto, percebe-se ao contrário do que se achava no passado como natural, mas sim o todo de um grande processo de desenvolvimento e transferência de cultura.

O destaque para o poder discricionário, cujo é concebido, entre nós, como uma certa margem de liberdade, concedida deliberadamente pelo legislador à Administração Estatal, a fim de que esta escolha o comportamento mais adequado para a realização de um determinado fim único e exclusivamente público. Assim, o poder dito discricionário não deverá jamais se confundir com a imprecisão da formação de comandos legais. Nesse sentido os denominados conceitos vagos ou conceitos indeterminados, de que o legislador largamente lança mão para exprimir as suas convicções são, simplesmente, o produto da impossibilidade prática ou simples dificuldade técnica, em que o legislador frequentemente se encontra. Para QUEIRÓ (1969), o rigor que exercem os órgãos estatais, possuem o dever, antes mesmo de exercerem por completo sua competência, exercitarem e refletirem por demais a interpretação da norma. Portanto decorrem os problemas de interpretação que abalam a línea tênue do que tens como poder discricionário ou autoritário seja da norma considerada moralmente boa ou má.

A relação entre o princípio para com as normas, é de que algo a ser realizado deverá atingir o maior limite possível dentro do que o conteúdo jurídico permite no conceito real fático. Na expressão de GALUPPO (1999), os princípios são comando de otimização, podendo serem estabelecidos em diferentes níveis, cujas devem respeitar o possível jurídico e realista. O contexto da lei se permite dizer que as regras dos comandos jurídicos devem fazer exatamente o que ela exige, dentro daquilo que se entende como ambiente fático e possível do ponto de vista jurídico.

Entende-se que a figura do Estado como o conhecemos, de certa maneira sempre foi possível sua identificação como ente capaz não só de produzir, mas também de ter o 
monopólio do direito. Mas, contudo, nem sempre foi assim, instituições concebiam o direito como sendo algo próprio atribuído a si, é o exemplo que retrata ADEODATO (1997), junto ao pátrio poder dado na sociedade pretérita romana, cuja detinha condições de posse do filho como mercadoria, e hoje limita-se a emancipação dada apenas com o decurso de tempo. Importante ressaltar que na sociedade alemã, há menos de dois séculos, segundo Jhering, os fatos ocorridos que envolviam ofensa a honra do indivíduo, era assim chancelado pelo Estado, a solução através de duelos.

\section{RESTRIÇÕES DO PODER LEGISLATIVO SUPREMO. O PODER DA DOUTRINA JURÍDICA. A CRÍTICA SOCIAL COMO AGENTE CAPAZ DE FORMAÇÃO DE OPINIÃO PÚBLICA JURÍDICA}

As determinações políticas ocorridas no Brasil dos últimos anos, ganha destaque na atuação muitas vezes desenfreada por decisões judiciais, e nesse quesito principal as sujeições praticadas ferem assuntos tipicamente e tradicionalmente discutidos no campo político, oriundos do processo democrático eleito pela maioria do povo. Causando assim, em muitas o desarranjo da vontade popular aquecida, fruto da insatisfação com que o rumo segue dos problemas que envolvem a sociedade no contexto arguido por ARGUELHES (2014).

Para MAUS (2000), o que se entende na gestão da moral e jurisprudência, cujas se aproximam, nos escritos modernos da decisão jurídica podendo-se observar as contradições dessas conclusões. Ainda destaca, para Ronald Dworkin, a ideia dominante do pensamento e premissa cujo direito e moral não deveriam ser individualizados na prática da jurisprudência. Pois o que busca esclarecer, segundo o autor, a moral e os princípios são próprios da conceituação do direito, ainda assim sem contar em alguns casos de amparo normativo, mas que de toda forma deve nortear a decisão justa. É possível observar em que a relação entre a moral conduzida no direito e as conviç̧ões populares de certa forma conseguem se relacionar dentro da sociedade. 
Para tanto o mundo real da natureza e o mundo da cultura, convergem para o dado e para a construção social. Como exemplo, os cientistas do ramo de exatas ou mesmo ciências biológicas abordam os dados, por outro lado a ciência social ocupa-se com as consequências da construção e aplicação ao espaço vivido pelos indivíduos. Desta forma, LEWANDOWSKI (2003), sugere de que o jurista vai além do mero ser, mas para adiante do dever ser. Não há que se limitar, portanto o conjunto de regras que precedem a análise jurídica, tampouco de forma lógica ou hierárquica na pirâmide de Kelsen, mas utilizada de forma sistemática, sintetizando a resultante do confronto de ideias valoradas pelo complexo dado factual histórico.

O Estado democrático de direito, conforme relata DURÃO (2009), permeia-se por tensões entre norma e política, todavia o direito é o agente regulador dessa dinâmica interpessoal ou da coletividade, por outro lado a política encarrega-se pela elaboração de programas de interesse coletivo colocando-os em prática, no entanto cada um está desenvolvendo numa reciprocidade de funções para com o outro. Desta forma a política tem a capacidade de instrumentalizar as normas jurídicas no condão da coercibilidade, e o direito por sua vez legitima as decisões políticas. Contudo, para que haja o fundamento aplicado dos princípios desse modelo de Estado, há necessidade de se reconstruir os inter-relacionamentos de soberania do povo, baseando-se na teoria discursiva, destacando-se de que a soberania está presente de forma dispersa em toda forma de comunicação além da esfera pública, no forte poder comunicativo, do qual neutraliza o poder da sociedade junto a grupos de pressão, mas no viés fortalece a opinião pública cuja norteia decisões e próprio poder administrativo do Estado institucional.

\section{CONCLUSÃO}

A expressão que melhor revela o poder cabível ao povo é a de controlar a Administração Pública, sendo, portanto, necessário a participação popular em todas as esferas Estatais, seja nos poderes Executivo, Legislativo e o próprio Judiciário. Nesse contexto conclui-se através dos instrumentos normativos e administrativos o meio pelo qual se pratica a fiscalização e revisão de rotina de toda e qualquer atividade da administração pública. E esses mesmos mecanismos ou 
instrumentos de fiscalização não podem ser restritos a um ou outro poder, mas sim para todas as esferas estatais, tanto mais a pessoa, órgão, ou qualquer setor que detenha a ordem pública, principalmente na fiscalização e concretude de projetos. Importante ressaltar que toda atividade pública busca em seu fim agregar valor legítimo a sociedade, além de prestar serviço a mesma, garantindo assim elevado grau de democracia. Portanto é natural o conflito entre interesses políticos, do povo e as instituições que operam a prestação pública, sendo nesse embate a oportunidade de guarda, fiscalização e desenvolvimento da sociedade.

\section{REFERÊNCIAS}

ADEODATO, João Maurício. Modernidade e direito. Revista da Esmape. Recife, v. 2, n. 6, p. 256, 1997.

ADORNO, Sérgio. Insegurança versus direitos humanos: entre a lei e a ordem. Tempo Social, v. 11, n. 2, p. 129-153, 1999.

ARALDI, Clademir Luís. Nietzsche e Paul Rée: Acerca da existência de impulsos altruístas. Cadernos Nietzsche, v. 37, n. 1, p. 71-87, 2016.

ARGUELHES, Diego Werneck. Poder não é querer: preferências restritivas e redesenho institucional no Supremo Tribunal Federal pós-democratização. Universitas Jus, v. 25, n. 1, 2014.

BARROSO, Luis Roberto; DE BARCELLOS, Ana Paula. O começo da história. A nova interpretação constitucional e o papel dos princípios no direito brasileiro. Revista de direito administrativo, v. 232, p. 141-176, 2003.

CUNHA, Sheila Santos. O controle social e seus instrumentos. Capital social, participação política e desenvolvimento local: atores da sociedade civil e políticas de desenvolvimento local na Bahia, 2003. 
DE AZEVEDO, Antonio Junqueira. O direito, ontem e hoje. Crítica ao neopositivismo constitucional e insuficiência dos direitos humanos. Revista da Faculdade de Direito, Universidade de São Paulo, v. 102, p. 579-590, 2007.

DURÃO, Aylton Barbieri. Habermas: os fundamentos do estado democrático de direito. TRANS/FORM/AÇÃO: REVISTA DE FILOSOFIA, v. 32, n. 1, 2009.

DWORKIN, Ronald. Levando os direitos a sério. São Paulo: Martins Fontes, 2010. p. 1-203.

FAGUNDES, Seabra. O princípio constitucional da igualdade perante a lei e o Poder Legislativo. Revista de Direito Administrativo, v. 41, p. 1-12, 1955.

GALUPPO, Marcelo. (Os Princípios Jurídicos No Estado Democrático De Direito: Ensaio Sobre O Modo De Sua Aplicação) Legal Principles and Rules in the Democratic Rule of Law: An Inquiry on How to Apply Them. Revista de Informação Legislativa, Brasília (Brazil) a, v. 36, p. 191-210, 1999.

HABERMAS, Jürgen; REPA, Luiz. Bestialidade e humanidade. Uma guerra no limite entre direito e moral, de Jürgen Habermas. Cadernos de Filosofia Alemã: Crítica e Modernidade, n. 5, p. 77-87, 1999.

HART, Herbert LA. O positivismo e a separação entre o direito e a moral. Hart, Herbert LA Ensaios sobre teoria do direito e filosofia. Trad. José Garcez Ghirardi e Lenita Maria Rimoli Esteves. Rev. tec. Ronaldo Porto Macedo Junior e Leonardo Gomes Penteado Rosa. Rio de Janeiro: Elsevier, 2010.

HUNT, Lynn. A invenção dos direitos humanos: uma história. Editora Companhia das Letras, 2009.

LAZZARINI, Álvaro. Abuso de poder x poder de polícia. Revista de Direito Administrativo, v. 203, p. 25-39, 1996.

LEWANDOWSKI, Enrique Ricardo. A formação da doutrina dos direitos fundamentais. Revista da Faculdade de Direito, Universidade de São Paulo, v. 98, p. 411-422, 2003. 
MAUS, Ingeborg. Judiciário como superego da sociedade: o papel da atividade jurisprudencial na "sociedade órfã". Novos estudos CEBRAP, v. 58, p. 183-202, 2000. QUEIRÓ, Afonso Rodrigues. Os limites do poder discricionário das autoridades administrativas. Revista de Direito Administrativo, v. 97, p. 1-8, 1969.

SANTOS, Ricardo Machado. Leis permissivas da razão e o problema das ações moralmente-indiferentes em Kant. Studia Kantiana, v. 10, n. 12, p. 64-76, 2012.

Enviado: Setembro, 2019.

Aprovado: Janeiro, 2020. 